\title{
IDENTIFICAÇÃO DE CULTIVARES E CERTIFICAÇÃO DA PUREZA GENÉTICA DE GLADÍOLO POR MEIO DE MARCADORES MORFOLÓGICOS
}

\author{
Identification of cultivars and certification of genetic purity of \\ gladiolus through morphologic markers
}

\author{
Clarissa Alves Ferreira ${ }^{1}$, Édila Vilela de Resende Von Pinho², Patrícia Duarte de Oliveira Paiva ${ }^{2}$, \\ Gabriella Santos Pereira ${ }^{2}$, Rafael Parreira Diniz ${ }^{2}$
}

\begin{abstract}
RESUMO
A caracterização de cultivares de flores é fundamental nos processos de registro e proteção dessas e também na certificação da pureza genética. Nesse trabalho foram realizadas a caracterização e a certificação da pureza genética de cultivares de Gladiolus sp. por meio de marcadores morfológicos. Utilizaram-se onze cultivares de Gladiolus sp., e para a caracterização das cultivares, as parcelas foram constituídas de 25 plantas avaliando-se características dos cormos, folhas e flores. O delineamento experimental adotado foi de blocos casualizados, com quatro repetições Para a certificação da pureza genética, foram instaladas parcelas constituídas de 24 plantas e cormos contendo contaminação varietal em diferentes proporções. Foram utilizadas três cultivares para compor os tratamentos e as avaliações foram conduzidas por três avaliadores que desconheciam a porcentagem existente de contaminação varietal. Foram calculadas as porcentagens de acerto e de erro com base nos resultados obtidos nas avaliações. Foi calculado o desvio padrão da média dos resultados nas quatro repetições, obtidos pelos três avaliadores. Para verificar a significância dos desvios entre os resultados obtidos pelos avaliadores foi utilizado o teste de qui-quadrado $\left(\chi^{2}\right)$. Por meio de características do cormo é possível diferenciar quatro cultivares das onze avaliadas. A característica da cor das flores é o descritor morfológico mais seguro para a diferenciação das cultivares de gladíolo. Dependendo das características das cultivares contaminantes e das cultivares em análises é possível utilizar descritores morfológicos para a certificação de pureza genética em cultivares de gladíolo.
\end{abstract}

Termos para indexação: Gladiolus sp, flores, contaminação varietal.

\section{ABSTRACT}

The characterization of flower cultivars is fundamental in the registration and protection processes and also in the genetic purity certification. In this work, both the characterization and the genetic purity certification of cultivars of Gladiolus sp by means of morphologic markers were made. Eleven cultivars of Gladiolus sp. were used and for the characterization of the cultivars, the plots were made up of 25 plants, evaluating the characteristics of corms, leaves and flowers. The used experimental design was the one of randomized blocks with four replicates. For the genetic purity certification, plots with 24 plants and corms containing varietal contaminations in different proportions were established. Three cultivars were used to make up the treatments, and the evaluations were conducted by three evaluators who were unaware of the existent percentage of varietal contamination. The percentage of mistakes was calculated based upon the obtained results of the evaluations. The standard deviation of the means of the results in the four replicates obtained by the three evaluators was calculated. In order to verify the significance of the deviations among the obtained results by the evaluators, Chi-square test $\left(\chi^{2}\right)$ was used. By means of corm characteristics, it is possible to distinguish four cultivars out of the eleven evaluated. The characteristic of flower color is the safest morphological descriptor for distinguishing gladiolus cultivars. Depending on the characteristics of the contaminant cultivars and on the ones under analyses, it is possible to use morphological descriptors for the genetic purity certification in gladiolus cultivars.

Index terms: Gladiolus sp., flowers, varietal contaminations.

(Recebido em 30 de abril de 2010 e aprovado em 21 de dezembro de 2010)

\section{INTRODUÇÃO}

O gladíolo tem grande importância como flor de corte e pertence à família botânica Iridaceae, subfamíla Ixioidea, envolvendo entre 250 a 300 espécies (REES, 1992; LANDGRAF e PAIVA, 2009). A propagação de gladíolo em escala comercial se faz por meio de cormos e cormilhos. Atualmente, nas empresas produtoras de cormos é monitorado todo o processo produtivo, visando a um produto com alta pureza genética, evitando-se principalmente as contaminações varietais.

Segundo Payne (1986), a avaliação da pureza genética é feita por meio da observação de determinadas características físicas dos materiais, comparando as amostras a serem testadas com uma amostra padrão da cultivar. Quando as diferenças morfológicas são facilmente visualizadas, tal avaliação possui vantagens como a

\footnotetext{
1DowAgroSciences Sementes \& Biotecnologia Brasil Ltda. - Avenida Antonio Diederichsen - 400 - sala 403 - B. Jardim América - 14020-250 - Ribeirão Preto, SP - caferreira@dow.com
}

${ }^{2}$ Universidade Federal de Lavras/UFLA - Departamento de Agricultura/DAG - Lavras, MG

Ciênc. agrotec., Lavras, v. 35, n. 4, p. 692-700, jul./ago., 2011 
rapidez, baixo custo e a pouca utilização de equipamentos. A maioria das novas cultivares, porém, possui características físicas muito semelhantes, que dificultam essa avaliação. Atualmente, em gladíolo, a pureza genética dos cormos tem sido avaliada por meio de marcadores morfológicos.

Um ponto fundamental para um marcador ser eficiente na seleção é que esteja intimamente ligado ao alelo que se deseja selecionar e sempre que um indivíduo expressa o fenótipo do marcador ele deverá também ser portador do alelo de interesse. Uma grande limitação dos marcadores morfológicos é a sua ocorrência em número reduzido e, consequentemente, insuficiente para marcar alelos de interesse de vários genes da espécie (RAMALHO et al., 2004).

Vale ressaltar que a avaliação de características morfológicas de plântulas e plantas adultas pode ser considerada uma vantagem no caso de identificação de cultivares, mas para a análise de pureza genética (SMITH; REGISTER III, 1998), a avaliação em estádios avançados de desenvolvimento para identificar contaminações em lotes de cormos pode atrasar as decisões sobre o destino do lote (RAMOS et al., 2006). Além disso, as características morfológicas podem variar em relação ao ambiente de produção, reduzindo a precisão dos resultados da análise da pureza genética (DITMER, 1979; SCHIMIDT, 1979; COOKE, 1984).

Apesar de apresentarem limitações por requererem tempo e espaço e muitos serem avaliados em plantas adultas, os marcadores morfológicos são tradicionalmente usados na caracterização de cultivares, para o registro e proteção de cultivares (VIEIRA et al., 2009). Por meio da caracterização morfológica é fornecida uma série de informações a respeito da variabilidade genética de cada acesso estudado (GUIMARÃES et al., 2007).

As pesquisas relacionadas com certificação da pureza genética em flores são insuficientes para a identificação das diferentes cultivares existentes. Em razão disso, objetivou-se, no trabalho, realizar a identificação e a certificação da pureza genética de cultivares de Gladilous sp. por meio de marcadores morfológicos.

\section{MATERIAL E MÉTODOS}

O trabalho foi conduzido na área experimental do Setor de Floricultura do Departamento de Agricultura, da Universidade Federal de Lavras, na cidade de Lavras, MG.

Foram utilizados cormos de onze cultivares diferentes de gladíolo, com perímetro de 10 a $12 \mathrm{~cm}$, provenientes da Empresa Terra Viva, localizada na cidade de Holambra, SP, como descritos na Tabela 1.
Para a caracterização das cultivares por meio de marcadores morfológicos, foi instalado um experimento em casa de vegetação, em delineamento de blocos casualizados. Cada bloco foi constituído de um canteiro (3,70 x 1,50 m), sendo os tratamentos, constituídos pelas diferentes cultivares, distribuídas ao acaso. Cada parcela foi composta de 25 plantas.

O preparo do solo para o plantio foi constituído de aração, seguida de gradagem e abertura de sulcos, com $15 \mathrm{~cm}$ de profundidade e espaçamento entre os sulcos de $40 \mathrm{~cm}$. Nas linhas, o espaçamento entre os cormos foi de 7 a $10 \mathrm{~cm}$. A adubação foi feita de acordo com a recomendação para a cultura e a irrigação foi utilizada quando necessária, pelo método de aspersão. $\mathrm{O}$ tutoramento foi iniciado quando as plantas apresentaram $30 \mathrm{~cm}$ de altura. Foram utilizadas ripas, colocadas ao longo da linha de cultivo.

Para o levantamento de características morfológicas para a diferenciação das cultivares, tanto em cormos, antes e após o plantio, como nas plantas em vários estágios de desenvolvimento foram avaliadas as seguintes características: peso, perímetro, cor da túnica, cor dos aros de inserção da túnica e cor dos cormos. No estádio vegetativo de plântulas e plantas foram avaliadas a cor, número e o tamanho (comprimento e maior largura) de folhas e a presença de antocianina nas folhas.

No estádio reprodutivo, avaliaram-se a cor da flor, porte da planta, tamanho da flor (comprimento e maior largura), número de flores, vida de vaso, comprimento da haste.

Para a análise estatística dos dados quantitativos, foi utilizado o teste de Scott-Knott 5\%, pelo "software" Sisvar, Versão 4.0 (FERREIRA, 1999).

Em um segundo experimento, foi realizada a certificação da pureza genética em cultivares de gladíolo por meio de marcadores morfológicos.

O experimento foi instalado em casa de vegetação do Setor de Floricultura. Foi utilizado delineamento de blocos casualizados, com quatro repetições. Cada bloco foi constituído de um canteiro $(3,40 \times 2,00 \mathrm{~m})$ e com três cultivares em análise e com três contaminantes, com valores de contaminação de uma segunda cultivar (Tabela 2). E cada parcela foi constituída por uma linha de 2,00 m de comprimento. A densidade foi de 24 plantas por parcela. $\mathrm{O}$ plantio, em cada parcela, foi realizado em linhas duplas, espaçadas de $10 \mathrm{~cm}$. A profundidade de plantio foi de $15 \mathrm{~cm}$ e o espaçamento entre os sulcos de $70 \mathrm{~cm}$. Nas linhas, o espaçamento entre os cormos foi de 7 a $10 \mathrm{~cm}$. Durante a semeadura, a localização dos cormos das cultivares contaminantes foi marcada com estacas. Após o desbaste, as estacas foram retiradas e o controle da posição das plantas contaminantes foi realizado por meio de um croqui. 
Tabela 1 - Descrição de diferentes cultivares de gladíolo utilizadas na pesquisa. UFLA, Lavras, MG.

\begin{tabular}{llcc}
\hline & \multicolumn{1}{c}{ Cultivares } & Floresc. (dias) & Coloração das Flores \\
\hline 1 & White Friendship & 65 & Branca \\
2 & White Goddess & 75 & Branca \\
3 & Priscilla & 75 & Rosa, Branca E Amarela \\
4 & Rose Friendship & 65 & Rosa \\
5 & San Martin & 75 & Rosa \\
6 & Gold Field & 85 & Amarela \\
7 & Yester & 85 & Amarela com o Centro Vermelho \\
8 & T 704 & 75 & Lilás \\
9 & Traderhorn & 75 & Vermelho Com Branco \\
10 & Red Beauty & 75 & Vermelho \\
11 & Peter Pears & 70 & Coral \\
\hline
\end{tabular}

Tabela 2 - Cultivares de gladíolo em análise e as contaminantes utilizadas na certificação da pureza genética das diferentes cultivares. UFLA, Lavras, MG.

\begin{tabular}{|c|c|c|c|}
\hline Cultivares em Análise & Contaminantes & Bloco & \% de Contaminação \\
\hline \multirow{4}{*}{1 White Friendship } & \multirow{4}{*}{2 White Goddess } & 1 & 4 \\
\hline & & 2 & 8 \\
\hline & & 3 & 0 \\
\hline & & 4 & 12 \\
\hline \multirow{4}{*}{6 Gold Field } & \multirow{4}{*}{11 Peter Pears } & 1 & 8 \\
\hline & & 2 & 16 \\
\hline & & 3 & 4 \\
\hline & & 4 & 4 \\
\hline \multirow{4}{*}{9 Traderhorn } & \multirow{4}{*}{4 Rose Friendship } & 1 & 0 \\
\hline & & 2 & 12 \\
\hline & & 3 & 12 \\
\hline & & 4 & 4 \\
\hline
\end{tabular}

Em cada parcela avaliada, foi realizado o plantio da cultivar em análise na linha, com o objetivo de facilitar a identificação das contaminantes. As avaliações foram realizadas por três avaliadores que desconheciam a porcentagem existente de contaminação. Os avaliadores foram previamente informados das características a serem observadas. As avaliações foram realizadas em cormos e em plantas, julgando quais eram provenientes de cada cultivar citada na Tabela 1 e quais eram contaminantes.

As plantas foram avaliadas no estádio vegetativo com 30 e 60 dias após o plantio e no estádio reprodutivo. Foram avaliados, ainda, os cormos, antes do plantio. Para essa avaliação, os cormos foram dispostos lado a lado em folhas de papel numerados e foi utilizado o mesmo delineamento, número de repetições e percentual de contaminantes utilizados no campo. Os avaliadores também consideraram outras características que julgaram importantes para diferenciar as cultivares.
Foram calculadas as porcentagens de acerto e de erro com base nos resultados obtidos das avaliações. A porcentagem de acerto foi calculada pelo quociente entre frequência observada e a frequência esperada, multiplicado por cem. No cálculo da porcentagem de erro, foram consideradas as plantas contaminantes que não foram identificadas pelos avaliadores e as não contaminantes que foram identificadas como contaminantes. $\mathrm{O}$ somatório dessas plantas foi dividido pelo número total de plantas na parcela e multiplicado por 100 .

Foi calculado o desvio padrão da média dos resultados nas quatro repetições, obtidos pelos três avaliadores, conforme Pimentel-Gomes (1987). Para verificar a significância dos desvios entre os resultados obtidos pelos avaliadores foi utilizado o teste de qui-quadrado $\left(\chi^{2}\right)$. Nesse teste, os desvios foram transformados em um único valor de $\chi^{2}$, representando a medida padronizada da magnitude dos desvios (RAMALHO et al., 2004). O valor de $\chi^{2}$ foi 
estimado pela seguinte expressão: $\chi^{2}=\Sigma(\mathrm{FO}-\mathrm{FE})^{2} / \mathrm{Fe}$, sendo: FO: frequência observada de plantas contaminantes; FE: frequência esperada de plantas contaminantes.

Os dados de frequência esperada e observada foram obtidos pela média das quatro repetições para cada avaliador.

\section{RESULTADOS E DISCUSSÃO}

Pelos resultados obtidos na caracterização das cultivares em casa de vegetação (Tabela 3 ), observou-se que, pela cor da túnica, só foi possível diferenciar a cultivar Traderhorn, que possui coloração rosa. Já por meio da coloração rosa da inserção da túnica, as cultivares San Martin, Gold Field e Peter Pears foram diferenciadas das demais, as quais possuem essa coloração dourada.

A cor dos cormos variou entre as cultivares, mas entre os tons de amarelo, a diferenciação não foi possível, sendo que cinco cultivares apresentaram cormos de coloração amarela (Tabela 3). A diferenciação de tonalidades de cores próximas pode ser influenciada pela luminosidade no momento de avaliação para a definição da cor (BONOW et al., 2007). Decorrente desse fato, tornase difícil a distinção das cultivares por esse descritor. A cor dos cormos é considerada um descritor importante, pois o quanto antes as cultivares forem diferenciadas melhor para o controle de qualidade na empresa produtora.

Por meio da cor das folhas, não foi possível separar as cultivares analisadas, exceto a Traderhorn que possui as folhas verdes arroxeadas (Tabela 3). As demais cultivares possuíam folhas de colorações verdes, variando apenas a tonalidade. Em razão da variação do nível de nitrogênio disponível no solo, deve-se tomar cuidado com a variação da cor da folha e, geralmente, nas folhas mais jovens essa tonalidade é alterada (BONOW et al., 2007).

Foi observada a presença de antocianina na primeira folha em todas as cultivares, exceto na cultivar Yester. Em alguns casos, a presença de antocianina era observada somente no nível do solo, o que dificulta sua rápida visualização. A presença de antocianina também foi observada em torno do limbo foliar da segunda folha da cultivar Red Beauty e na ponta das primeiras folhas somente na cultivar White Goddess (Tabela 3). Nessa última, no entanto, foi observada somente no início do ciclo, provavelmente, em razão de fatores ambientais. Segundo Bonow et al. (2007), em arroz, a herança da pigmentação de antocioaninaé bastante complexa, pois existem locos duplicados, série alélica múltipla para o mesmo loco. Na presente pesquisa, foram observadas pequenas diferenças na tonalidade e intensidade da cor entre os genótipos e essa variação pode ser decorrente dos estádios de crescimento, fatores inibidores e/ou ambientais sobre o desenvolvimento da cor, como a luz, por exemplo.

A cor das flores foi o descritor mais seguro para diferenciar as cultivares pois, desse modo, foi possível separar todas as cultivares analisadas (Tabela 3). Esse descritor, contudo, pode ser observado somente na fase do florescimento da cultura, o que o torna inviável em programas de controle de qualidade, visto que o ideal é que o contaminante seja identificado o mais cedo possível para o não comprometimento da comercialização. O porte da planta foi um marcador por meio do qual foi possível separar as cultivares em três grupos: porte alto, médio e baixo, sendo classificadas as cultivares White Friendship e Rose Friendship como de porte baixo, Gold Field, Red Beauty e Peter Pears como de porte alto e as demais como de porte médio (Tabela 3).

Algumas características morfológicas podem ser facilmente distintas, pois apresentam segregação descontínua e são denominadas de características qualitativas. Entretanto, existem características que possuem uma distribuição essencialmente contínua, ou seja, entre os tipos mais extremos aparecem fenótipos intermediários (RAMALHO et al., 2004).

Tanto o comprimento como a largura do limbo foliar diferiu entre as cultivares, tanto nos 30 dias após o plantio quanto na época da emissão da espiga (Tabela 4). Somente as cultivares Gold Field e Red Beauty mantiveram o maior comprimento e maior largura do limbo foliar durante todo o ciclo da cultura. A cultivar Peter Pears estava pouco desenvolvida aos 30 dias e não pode ser avaliada, mas quando ocorreu a emissão da espiga, essa cultivar tinha o maior comprimento da folha e a segunda maior largura dentre as demais cultivares, logo, essa característica é pouco estável, ocorrendo considerável variação entre as cultivares nas diferentes épocas analisadas. Mota et al. (2006) trabalharam com essa característica e conseguiu diferenciar as cultivares de alho dentro do grupo seminobre, já para as cultivares do grupo nobre não foi possível a diferenciação.

Por meio do número de folhas aos 30 dias após o plantio, foi possível diferenciar as cultivares em dois grupos. Somente as cultivares Peter Pears e San Martin possuíam um menor número de folhas em relação às outras (Tabela 4). Quando foi realizada uma avaliação nas cultivares no momento da emissão da espiga, o número de folhas diferenciou a cultivar Gold Field, com o maior número em relação às demais (Tabela 4). Mota et al. (2006) também diferenciou cultivares de alho dentro do grupo seminobre e nobre por meio do número médio de folhas. 


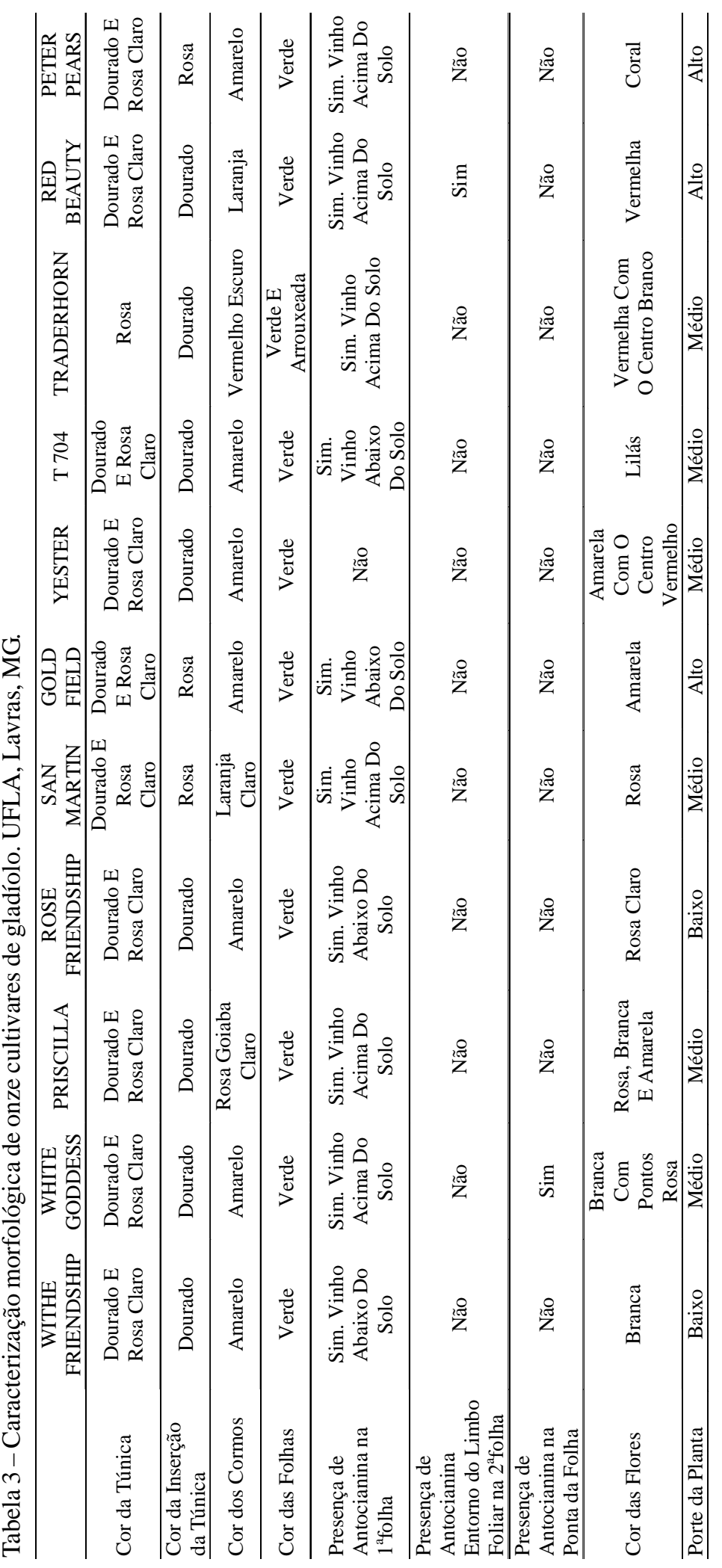

Ciênc. agrotec., Lavras, v. 35, n. 4, p. 692-700, jul./ago., 2011 


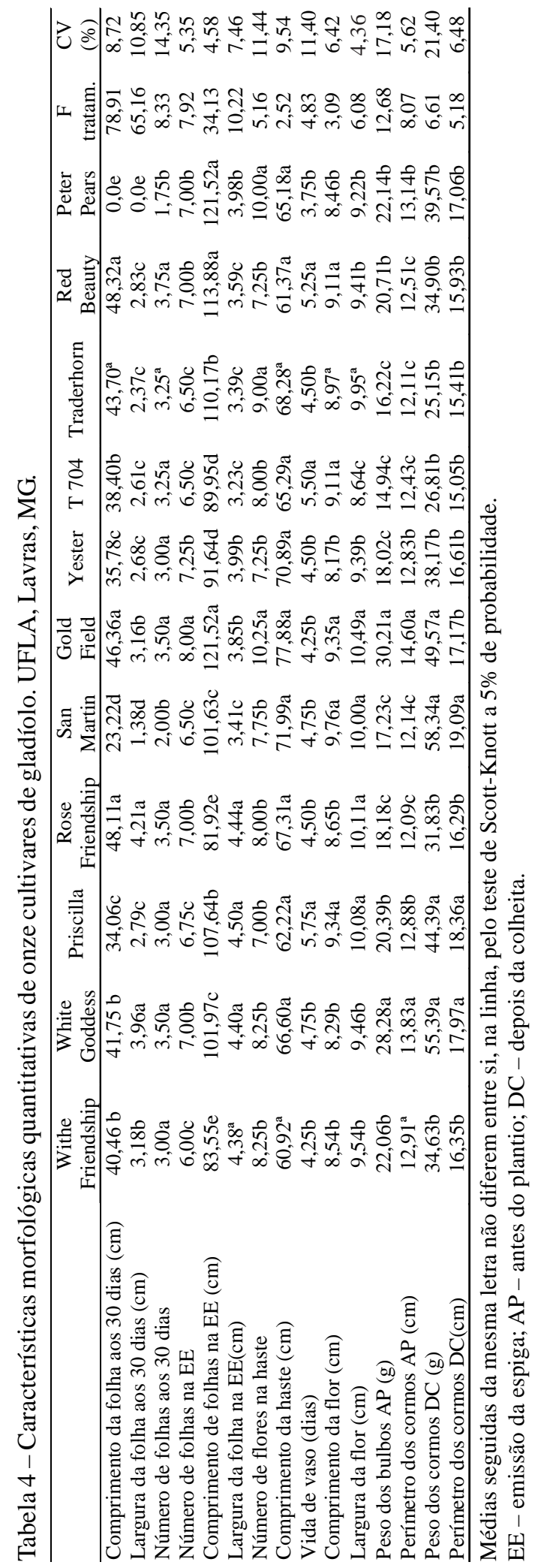


Pelo número de flores e a vida de vaso separaramse as cultivares em dois grupos (Tabela 4). No primeiro, apenas nas cultivares Gold Field, Traderhorn e Peter Pears foi observado um número maior de flores em relação às outras cultivares. As cultivares que tiveram maior vida de vaso foram Priscilla, T-704 e Red Beauty, tempo esse correspondente a cinco dias, em média.

Por meio do comprimento da haste floral, não foi possível distinguir as cultivares (Tabela 4). As maiores flores, considerando o maior comprimento e a maior largura da flor, foram das cultivares Priscilla, San Martin, Gold Field e Traderhorn. O peso e o perímetro dos cormos avaliados antes do plantio permitiram o agrupamento das cultivares em três grupos (Tabela 4). As cultivares White Goddess e Gold Field apresentaram os maiores pesos e perímetros simultaneamente quando avaliados antes do plantio. Mas, na avaliação após a colheita, o peso e o perímetro dos cormos permitiram diferenciar as cultivares apenas em dois grupos (Tabela 4). As cultivares que apresentaram os maiores pesos e perímetros foram a White Goddess e San Martin. Em alho, foi possível distinguir cultivares por meio desse descritor (MOTA et al., 2006).

É importante mencionar que durante as avaliações foram encontradas contaminações nas parcelas, tanto no primeiro experimento quanto no segundo. Essas já vieram no próprio material que foi adquirido. Sendo assim, podese concluir que realmente é necessário um programa de certificação de pureza genética dos cormos que são comercializados.

A partir dos resultados obtidos, é possível inferir que, para as características avaliadas, foi possível agrupamento das cultivares, exceto para o comprimento da haste das flores. É importante ressaltar que, para a diferenciação das cultivares, devem ser realizadas análises de mais de uma característica dos cormos ou das plantas e a comparação dessas deve ocorrer sob o mesmo ambiente para evitar a influência de fatores ambientais.

$\mathrm{Na}$ Tabela 5, estão apresentados os resultados médios dos porcentuais de acerto e de erro obtidos durante a certificação da pureza genética das cultivares estudadas.

$\mathrm{Na}$ avaliação efetuada nos cormos, para a cultivar Traderhorn, houve uma porcentagem de acerto de $100 \%$. A principal característica observada pelos avaliadores foi a cor do cormo, avermelhada, que era bastante diferente do contaminante. A menor porcentagem de acerto ocorreu para a cultivar White Friendship, com apenas $48,83 \%$. Atribui-se a esses resultados o fato de tanto a cultivar White Friendship e seu contaminante possuírem cormos amarelos, variando apenas na intensidade da cor, o que provavelmente tenha dificultado a identificação.

$\mathrm{Na}$ avaliação realizada 30 dias após o plantio, a maior porcentagem de acerto, $88,89 \%$ e a menor porcentagem de erro, $8,66 \%$ foram observadas para a cultivar Traderhorn (Tabela 5). Essa alta porcentagem de acerto foi obtida pela presença acentuada da cor verde arroxeada das folhas, de folhas finas e do porte médio da cultivar Traderhorn, o que a diferenciou em relação ao contaminante que possui a cor das folhas na tonalidade de verde, folhas largas e porte baixo. A cultivar Gold Field e seu contaminante apresentam ciclos bem distintos, que torna fácil sua diferenciação. A porcentagem de acerto observada para essa cultivar foi de $72,92 \%$. Na cultivar White Friendship, observou-se a menor porcentagem de acerto, $15,28 \%$ e a maior porcentagem de erro, $17,68 \%$. A diferenciação entre essas cultivares foi dificultada pelo fato dessas duas cultivares apresentarem descritores bem semelhantes.

Aos 60 dias após o plantio, todos os contaminantes foram diferenciados das outras cultivares com a maior porcentagem de acerto e menor porcentagem de erro que na avaliação anterior (Tabela 5). Nessa fase, a maioria das cultivares encontrava-se entre a fase da emissão da espiga e a de florescimento, facilitando assim a diferenciação em função dos ciclos das cultivares, principalmente considerando-se a cultivar Gold Field e seu contaminante. Outra característica importante na diferenciação entre a cultivar Tradehorn e seu contaminante foi o porte de plantas, o que não ocorreu na diferenciação das outras cultivares. Já, para a cultivar White Friendship e seu contaminante, a separação tornou-se difícil, pelo fato de possuírem porte bem semelhante.

No florescimento, a avaliação permitiu a total separação das cultivares e de seus contaminantes, com uma porcentagem de acerto de $100 \%$ e uma porcentagem de erro de $0 \%$ (Tabela 5). A principal característica que permitiu a diferenciação foi a coloração das flores. A cultivar White Friendship, que possui flores brancas, foi separada do seu contaminante por meio de pontuações rosas que aparecem nas flores dessa última.

Segundo Salgado et al. (2006), a escolha do estádio para análise da pureza genética depende do objetivo da avaliação. Pinho et al. (1997) concluíram que é mais 
interessante a identificação de contaminantes em um programa de controle de qualidade na produção de milho no estádio de plântulas, por permitir a análise da pureza genética após a colheita e antes da comercialização das sementes. No caso da produção de cormos de gladíolo, o interessante é identificar os cormos contaminantes a fim de evitar o plantio de materiais diferentes no campo, pois o desbaste de contaminantes no campo é uma operação bem trabalhosa. Neste estudo a coloração do cormo permitiu separar as cultivares Priscilla (Rosa goiaba), San Matin (Laranja claro), Traderhorn (Vermelho escuro) e Red Beauty (Laranja).

Pode-se afirmar que a identificação dos contaminantes em estádios mais avançados de desenvolvimento das plantas é mais segura, com exceção da avaliação de caracterização nos cormos, para a diferenciação da cultivar White Friendship e de seu contaminante (Tabela 5).

Pode-se observar que não houve significância dos desvios entre os resultados obtidos pelos três avaliadores (Tabela 6). É importante esclarecer que, quando ocorreu a não significância dos desvios na avaliação, os erros foram decorrentes do acaso (erro amostral). Assim, aceitam-se as variações que ocorreram entre os resultados obtidos pelos três avaliadores.

As avaliações realizadas nas cultivares Traderhorn e na Gold Field, independentemente da época, apresentaram baixos valores de qui-quadrado juntamente com as altas taxas de acerto e as baixas porcentagens de erro, indicando ser possível a separação dessas cultivares de seus respectivos contaminantes por meio de marcadores morfológicos.

Tabela 5 - Resultados de identificação (\% de acerto e \% de erro) de cormos e plantas provenientes de diferentes cultivares de gladíolo em várias épocas de avaliação. UFLA, Lavras, MG.

\begin{tabular}{|c|c|c|c|c|c|}
\hline \multirow[b]{2}{*}{ Cultivar } & & \multicolumn{4}{|c|}{ Épocas de Avaliação } \\
\hline & & Cormos & 30 dias AP & 60 dias AP & Florescim. \\
\hline White & $\%$ acerto & $48,83 \pm 26,02 *$ & $15,28 \pm 21,28$ & $23,61 \pm 15,91$ & $100,0 \pm 0,0$ \\
\hline Friendship & $\%$ erro & $0,18 \pm 0,09$ & $17,68 \pm 10,33$ & $17,47 \pm 8,01$ & $0,0 \pm 0,0$ \\
\hline \multirow[t]{2}{*}{ Gold field } & $\%$ acerto & $91,66 \pm 14,43$ & $72,92 \pm 41,61$ & $75,0 \pm 33,07$ & $100,0 \pm 0,0$ \\
\hline & $\%$ erro & $0,02 \pm 0,02$ & $17,63 \pm 21,13$ & $16,93 \pm 22,36$ & $0,0 \pm 0,0$ \\
\hline \multirow[t]{2}{*}{ Traderhorn } & $\%$ acerto & $100,0 \pm 0,0$ & $88,89 \pm 12,73$ & $94,45 \pm 4,81$ & $100,0 \pm 0,0$ \\
\hline & $\%$ erro & $0,02 \pm 0,04$ & $8,66 \pm 13,11$ & $5,05 \pm 6,90$ & $0,0 \pm 0,0$ \\
\hline
\end{tabular}

* - Desvio padrão da média.

AP - após o plantio.

Tabela 6 - Resultados do teste de qui-quadrado $\left(\chi^{2}\right)$, aplicados aos dados de identificação de cormos e plantas provenientes de diferentes cultivares de gladíoloass2adas, em várias épocas de avaliação, obtidos por três avaliadores. Lavras, MG.

\begin{tabular}{|c|c|c|c|c|c|}
\hline \multirow[b]{2}{*}{ Cultivar } & \multirow[b]{2}{*}{ Avaliador } & \multicolumn{4}{|c|}{ Épocas de Avaliação } \\
\hline & & Cormos & 30 dias AP & 60 dias AP & Florescimento \\
\hline \multirow{4}{*}{$\begin{array}{c}\text { White } \\
\text { Friendship }\end{array}$} & 1 & 0,17 & 0,63 & 1,23 & 0 \\
\hline & 2 & 1,50 & 2,03 & 0,90 & 0 \\
\hline & 3 & 1,04 & 2,50 & 2,03 & 0 \\
\hline & $\chi^{2}$ & $2,71 \mathrm{NS}$ & $5,15 \mathrm{NS}$ & $4,15 \mathrm{NS}$ & $0 \mathrm{NS}$ \\
\hline \multirow{4}{*}{ Gold Field } & 1 & 0,0 & 0,04 & 1,29 & 0 \\
\hline & 2 & 0,03 & 1,75 & 0,14 & 0 \\
\hline & 3 & 0,0 & 0 & 0 & $0 \mathrm{NS}$ \\
\hline & $\chi^{2}$ & $0,03 \mathrm{NS}$ & $1,79 \mathrm{NS}$ & $1,43 \mathrm{NS}$ & 0 \\
\hline \multirow{4}{*}{ Traderhorn } & 1 & 0,0 & 0,32 & 0,0 & 0 \\
\hline & 2 & 0,0 & 0,0 & 0,04 & 0 \\
\hline & 3 & 0 & 0,04 & 0,04 & 0 \\
\hline & $\chi^{2}$ & $0 \mathrm{NS}$ & $0,36 \mathrm{NS}$ & $0,08 \mathrm{NS}$ & $0 \mathrm{NS}$ \\
\hline
\end{tabular}

* NS - Não significativo. 


\section{CONCLUSÃO}

Por meio de características do cormo de gladíolo é possível diferenciar quatro cultivares das onze avaliadas. A característica cor das flores é o descritor morfológico mais seguro para a diferenciação das cultivares de gladíolo. Dependendo das características das cultivares contaminantes e das em análises é possível utilizar descritores morfológicos para a certificação de pureza genética em cultivares de gladíolo.

\section{REFERÊNCIAS BIBLIOGRÁFICAS}

BONOW, S.; PINHO, E.V. de R. von; SOARES, A.A. Caracterização morfológica de cultivares de arroz visando a certificação da pureza varietal. Ciência e Agrotecnologia, Lavras, v.31, n.3, p.619-627, maio/jun. 2007.

COOKE, R.J. The characterization and identification of crop cultivars by electrophoresis. Electrophoresis, Weinheim, v.5, p.59-72, 1984.

DITMER, W.P. Varital determination made in the seed laboratory. Journal of Seed Technology, Zurich, v.3, n.2, p.42-47, 1979.

FERREIRA, D.F. Sisvar - sistema de análise de variância para dados balanceados. Versão 4.0. Lavras: DEX/UFLA, 1999. Software.

GUIMARÃES, W.N.R. et al. Caracterização morfológica e molecular de acessos de feijão-fava (Phaseolus lunatus L.). Revista Brasileira de Engenharia Agrícola e Ambiental, Campina Grande, v.11, n.1, p.37-45, 2007.

LANDGRAF, P.R.C.; PAIVA, P.D.O. Produção de flores cortadas no estado de Minas Gerais. Ciência e Agrotecnologia, Lavras, v.33, n.1, p.120-126, jan./fev. 2009.

MOTA, J.H. et al. Similaridade genética de cultivares de alho pela comparação de caracteres morfológicos, físicoquímicos, produtivos e moleculares. Horticultura Brasileira, Brasília, v.24, n.2, p.156-160, 2006.
PAYNE, R.C. Cultivar testing by official AOSA seed laboratories. Journal of Seed Technology, Lansing, v.10, n.1, p.24-36, 1986.

PIMENTEL-GOMES, F. Curso de estatística experimental. 12.ed. Piracicaba: ESALQ/USP, 1987. 466p.

PINHO, E.V.R. von; PINHO, R.Z. von; CICERO, S.M. Utilização de características morfológicas para avaliação da pureza genética em sementes híbridas de milho.

Pesquisa Agropecuária Brasileira, Brasília, v.32, n.9, p.941-949, set. 1997.

RAMALHO, M.A.P.; SANTOS, J.B.; PINTO, C.A.B.P. Genética na agropecuária. 3.ed. São Paulo: UFLA, 2004. 472p.

RAMOS, N.P. et al. Sensibilidade dos microssatélites para determinar a pureza varietal em sementes de milho. Revista Brasileira de Sementes, Brasília, v.28, n.1, p.99105, 2006.

REES, A.P. Ornamental corms, corms and tubers. Wallingford: CAB International, 1992. 220p.

SALGADO, K.C.P.C. et al. Genetic purity certificate in seeds of hybrid maize using molecular markers. Revista Brasileira de Sementes, Pelotas, v.28, n.1, p.169-175, 2006.

SCHMIDT, J. W. A plant breeder looks at the problem of distinguinshing cultivars. Journal of Seed Technology, Lansing, 3 (2): 57-60, 1979.

SMITH, J.S.C.; REGISTER III, J.C. Genetic purity and testing rechnologies for seed quality: a company perspective. Seed Science Research, Wallingford, v.8, n.2, p.285-293, June 1998.

VIEIRA, E.S.N. et al. Caracterização de cultivares de soja por meio de descritores morfológicos e marcadores bioquímicos de proteínas e isoenzimas. Revista Brasileira de Sementes, Brasília, v.31, p.53-63, 2009. 